\title{
WHO mulls closer ties to private sector
}

$\mathrm{T}$ he World Health Organization (WHO) is rewriting the rules that govern how it interacts with the private sector to allow for more flexible and potentially lucrative partnerships. But some health advocates and governments fear the agency is also opening itself to undue corporate influence.

WHO member states are drafting a framework for engagement with "nonstate actors" (FENSA) to guide the agency's dealings with private entities, public interest groups and academic institutions. These include opening new channels for businesses, private foundations and industry associations to "support" WHO work, for example, through staff secondments, financial contributions, and participating in meetings that were previously off limits to private entities.

"If we under-engage we are not relevant and if we mis-engage we risk our reputation; on both sides there's a risk we have to manage," says Dr. Gaudenz Silberschmidt, WHO Director for Partnerships and Non-State Actors. Avoiding conflicts of interest in partnerships is "close to impossible," he argues. For this reason, WHO is seeking maximum flexibility to pursue opportunities wherever the benefits outweigh the risks.

"With some companies we will be very, very cautious; with others we might be in dialog but we won't accept funding because we want to keep our independence," Silberschmidt says. But beyond an explicit ban on working with the tobacco and arms industries, "the fine line of what you do or don't do needs to be looked at on a case-bycase basis."

Under recent iterations of the framework, those decisions will be made at the discretion of Silberschmidt's unit and reported annually to WHO's executive board. Wealthy countries like the United States and Canada have supported this discretionary approach.

According to a spokesperson, the Public Health Agency of Canada is satisfied that WHO will implement the necessary safeguards to protect the agency from "real or perceived" interference.

However, representatives from developing countries have pushed for stronger protections, particularly when

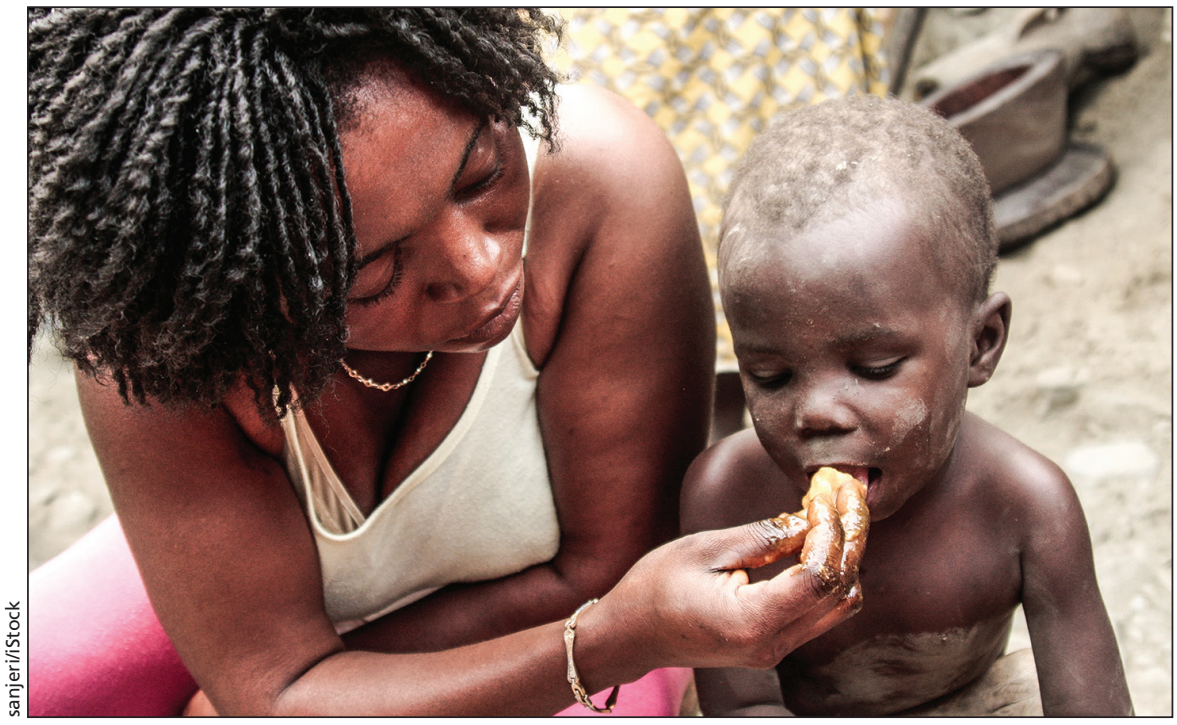

Developing countries urge the World Health Organization to reconsider closer ties with food industry and other private entities.

it comes to interactions with the pharmaceutical and food industries.

"A lot of the companies that produce junk foods and alcoholic beverages see developing markets as a good place to increase their dividends," says Bill Jeffery, National Coordinator of the Centre for Science in the Public Interest (CSPI), who attended the recent FENSA negotiations. "If governments in developing countries can't depend on WHO's integrity, they'll always have to wonder if what they're hearing is shaped by the agency's funders."

In an open letter, CSPI and some 60 other public interest groups argue that WHO "does not have transparent and effective policies and tools to prevent such undue influences and risks."

The current framework is "too vague" in the absence of such policies, says Jeffery.

Leaked communications from the International Food and Beverage Alliance published in The Times of India show that industry associations in Canada and the US are already pressuring WHO-member countries to refuse "any document that excludes the food and beverage industry." The communication also notes that Canada, Western Europe, Australia, Israel, New Zealand and the US are in "full alignment" with the industry's position.
Jeffery and other public health advocates are skeptical that WHO is prepared to withstand these pressures given recent financial difficulties.

Four out of every five dollars the agency receives are earmarked by donors for specific programs, leaving a funding shortfall for its core functions and hampering its response in emergencies.

According to Silberschmidt, "funding is the least of reasons" for increasing WHO's engagement with private entities: “... it's all about partnerships and how we can work together."

WHO plans to mitigate conflicts of interest and industry influence by publicly reporting all partnerships through a register of non-state actors. "That means the world can see what we are doing with whom, which allows us to do more partnerships while protecting us from those which we couldn't defend publicly," Silberschmidt says.

Using FENSA negotiations to hash out a complete conflict-of-interest policy would result in "micromanagement," he adds. "You could negotiate for 10 years and you probably wouldn't get it. We're making policy, not detailed procedures."

The draft framework will be open to revisions by member states until the World Health Assembly in May 2016. — Lauren Vogel, CMAJ

CMAJ 2016. DOI:10.1503/cmaj.109-5211 